\title{
¿Variability in Activation Properties in Relation to Meteorological Phenomena
}

\author{
N. Zíková, ${ }^{\mathrm{a}}$ P. Pokorná, ${ }^{\mathrm{a}}$ O. Makeš,,${ }^{\mathrm{a}, \mathrm{b}} \mathrm{J}$. Rotrekl, ${ }^{\mathrm{a}}$ P. Sedlák, ${ }^{\mathrm{c}}$ P. Pešice, ${ }^{\mathrm{c}}$ ANd V. Ždímal ${ }^{\mathrm{a}}$ \\ ${ }^{a}$ Department of Aerosol Chemistry and Physics, Institute of Chemical Process Fundamentals, Czech Academy of Sciences, \\ Prague, Czech Republic \\ ${ }^{\mathrm{b}}$ Institute for Environmental Studies, Faculty of Science, Charles University in Prague, Prague, Czech Republic \\ ${ }^{\mathrm{c}}$ Department of Meteorology, Institute of Atmospheric Physics, Czech Academy of Sciences, Prague, Czech Republic
}

(Manuscript received 31 March 2021, in final form 7 June 2021)

\begin{abstract}
In situ campaigns focused on aerosol-cloud interactions were performed to describe the size-dependent activation of aerosols of various origins during variable meteorological conditions. Low cloud episodes, coded as fog, freezing fog, or rain with fog, were compared with nonphenomenon episodes. From the difference in aerosols measured behind the whole air inlet and $\mathrm{PM}_{2.5}$ inlet, the activated fraction (AF; a share of activated particles from all those available) was calculated. For fog, the AF was stable, resulting in a small variability in the activated size. During freezing fog, a higher variability in supersaturation was deduced from larger variability in the AF and smaller effective radii of cloud droplets. The AF during rain with fog showed a connection to the air mass origin, less effective activation, and smaller cloud droplets. The analysis of the relationship between meteorological conditions and activations suggested that the different hydrometeors were connected with different air masses. No effect of photochemistry was found; in contrast, some dependence on relative humidity, temperature, wind speed, and liquid water content (LWC) was described. With increasing humidity, smaller particles were able to activate. For lower $\mathrm{RH}$, the importance of supersaturation fluctuations increased, moving to a fluctuation-influenced regime. The strongest connection was found between activation and LWC; for the LWC below $0.10 \mathrm{~g} \mathrm{~m}^{-3}$, a strong decrease in activated particle size was found with increasing LWC, due to turbulence, number of particles, and availability of condensable water. From $0.10 \mathrm{~g} \mathrm{~m}^{-3} \mathrm{LWC}$ and higher, the LWC and the connected supersaturation could be the main factors influencing the activation.
\end{abstract}

KEYWORDS: Aerosols; In situ atmospheric observations; Aerosol-cloud interaction

\section{Introduction}

The process of activation of atmospheric aerosol (AA) particles into cloud droplets, i.e., hygroscopic growth into droplets that can grow by water vapor condensation, is currently one of the most studied aerosol-related topics. An accurate activation description is necessary for estimating indirect climate effects (Barahona et al. 2010), for understanding the dynamics and microphysics of clouds (Reutter et al. 2009), and for increasing the accuracy of future climate predictions (Paramonov et al. 2015).

Particles that serve as nuclei for water vapor condensation are called cloud condensation nuclei $(\mathrm{CCN})$, and their numbers depend on the AA properties and water vapor supersaturation $S$. The AA properties typically described as crucial are the total number of AAs, aerosol particle number size distribution (PNSD), and hygroscopicity (Reutter et al. 2009; Paramonov et al. 2015). However, all crucial properties of aerosols are linked together.

๖ Denotes content that is immediately available upon publication as open access.

Supplemental information related to this paper is available at the Journals Online website: https://doi.org/10.1175/JHM-D-210064.s1.

Corresponding author: N. Zíková, zikova@icpf.cas.cz
In the regions with high numbers of particles, i.e., close to pollution sources, the concentrations can limit supersaturation, which usually remains below $0.3 \%$ (Ditas et al. 2012), and more hydrophobic aerosols would be expected. In relatively clean regions (total aerosol concentrations below $10000 \mathrm{~cm}^{-3}$ ), aerosols below $100 \mathrm{~nm}$ were reported to be activated (Henning et al. 2002), and the variability in the cloud droplet distribution was mostly affected by aerosol particle number concentration in the accumulation mode (Reutter et al. 2009; Jurányi et al. 2010). The cloud droplet distribution can be potentially broadened by updraft velocity variations. The updraft controls the maximum supersaturation (through the cooling rate that increases $S$ ), which determines the smallest particles that can activate (Sanchez et al. 2016); this diameter is usually called the critical diameter $D_{c}$. All particles larger than $D_{c}$ would be activated into cloud droplets (in the presence of a sufficient amount of water vapor). Some large particles, however, contribute substantially to the liquid water content (LWC), although they are not activated, as they cannot reach their critical size (Barahona et al. 2010). Supersaturation is a function of cooling (Sanchez et al. 2016), cloud base updraft velocity (Seinfeld et al. 2016), aerosol composition (Petters and Kreidenweis 2007; Mircea et al. 2002; Svenningsson et al. 2006), etc.

The aerosol composition and AA size are also strongly related to hygroscopicity. A combination of highly time-resolved aerosol number size distribution data with a mean chemical composition should suffice for an accurate CCN number estimate (under given supersaturation) (Jurányi et al. 2010). 
Paramonov et al. (2015) even suggested that the mean total number concentration of AAs is sufficient for a general estimate of the annual mean CCN concentration at any given $S$. The chemical aspects of aerosol activation are studied less intensively than particle size, which is assumed to be the main factor (Dusek et al. 2006; Jurányi et al. 2010) and applies to the formation of fog.

The importance of inorganic ions in fog formation was shown by Shimadera et al. (2009), and an increase in aerosol hygroscopicity by secondary aerosol formation or generally by aging (Paramonov et al. 2015) has been described even for black carbon (Motos et al. 2019). The characterization of the organic molecules forming aerosol particles is complicated, which are often crucial in heavily polluted areas (Zhang et al. 2015). The range of possible organics is broad, including both hydrophilic (soluble or partially soluble) and hydrophobic molecules (Rangognio et al. 2009) with contradictory behavior in the process of aerosol activation. Although the hygroscopicity of organic species is generally lower than that of inorganics (Petters and Kreidenweis 2007, 2008), organic molecules seem to participate significantly in the formation of aerosols in fog (Mandariya et al. 2019; Kim et al. 2019).

At low supersaturation levels (mainly below $0.3 \%$ ), the effects of AA size distribution and hygroscopicity on $\mathrm{CCN}$ concentrations are also more pronounced, and any simplifications are connected with large uncertainties (Paramonov et al. 2015), as the CCN concentrations at low $S$ are more sensitive to chemical composition changes than at higher $S$ (Jurányi et al. 2010). To lower the uncertainties concerning the cloud effect on the climate-the largest uncertainty in the radiative forcing estimates (Boucher et al. 2013) — the updraft-limited regimes of activation with low $S$ are crucial (Reutter et al. 2009). Even small differences in activation have a large impact on clouds and radiation at the global scale (Rothenberg et al. 2018).

Recently, the influence of turbulence-induced fluctuations in humidity, temperature, and supersaturation has been described, with moisture field variability being the main contributor to fluctuations in the saturation field (Siebert and Shaw 2017). These fluctuations, resulting from entrainment and mixing, fluctuations in vertical velocities, etc., may be included in the CCN activation models (Abade et al. 2018) or estimated from in situ measurements (Korolev and Mazin 2003). The fluctuations influence clouds by, for example, broadening the droplet size distribution (Prabhakaran et al. 2020; Abade et al. 2018) and may be as important as chemical inhomogeneity or CCN spectra polydispersity (Prabhakaran et al. 2020), with effects equivalent to those of observed during aerosol-limited and updraft-limited regimes (Shawon et al. 2021). The resulting activation could be highly variable in both time and space (Siebert and Shaw 2017).

To describe the dependence of activation on these changeable ambient variables, a robust dataset is necessary to enable keeping some of the factors fixed (Sorooshian et al. 2019). The relationship between aerosols and meteorological variables is not one-way; however, aerosol-induced meteorological changes are often ignored (Gao et al. 2015). Aerosols induce stability in the atmosphere by increasing the temperature below and within the aerosol layer (Kushta et al. 2014), further helping aerosols to accumulate in the atmosphere. The accumulation could affect the size distribution of aerosols and thus could influence activation again.

The main goals of this paper are to 1) contribute to a better understanding of the dependence of aerosol size-dependent activation on its origin under a wide variety of meteorological conditions using in situ cloud measurements, 2) increase the spatiotemporal coverage of information on aerosol activation, and 3) describe the interactions between aerosol and hydrometeors at various meteorological conditions.

\section{Methods}

\section{a. Sampling location}

Measurements were performed at the Milešovka observatory of the Institute of Atmospheric Physics of the Czech Academy of Sciences, located on top of an isolated conical mountain, rising $400 \mathrm{~m}$ above the surrounding terrain $\left(50^{\circ} 33^{\prime} 17^{\prime \prime} \mathrm{N}, 13^{\circ} 55^{\prime} 57^{\prime \prime} \mathrm{E}\right.$; $837 \mathrm{~m} \mathrm{MSL}$ ). At the observatory, meteorological observations were performed, and additional sampling of rain and fog water and rime was conducted, as fog occurred in more than $50 \%$ of the days per year (Fišák et al. 2009).

\section{b. Instrumentation}

At the observatory, the set of instruments typically used for the meteorological measurements has been used, with added aerosol instrumentation.

\section{1) Meteorological VARiables}

Typical meteorological data (temperature, relative humidity, dewpoint temperature, wind speed and direction) were measured continuously. The accuracy of humidity measurements (HMP45D, Vaisala, Finland) was $\pm 3 \%$ at $90 \%-100 \%$ RH; thus, the measurements under cloudy conditions may not have fully covered the variability in the moisture field (Siebert and Shaw 2017). Visibility measurements with hydrometeor type determination were performed simultaneously using the present weather detector (PWD52, Vaisala, Finland).

For the activation studies, periods with fog, freezing fog, and rain (WMO Code Table 4680, code groups 30 and 60) were considered, and for comparison, periods without any phenomena coded (code 0 , used as a background conditions) were also analyzed. Fog was classified as episodes with visibility below $1000 \mathrm{~m}$ (calculated from the extinction coefficient measured by the PWD), and for freezing fog, the same applied with additional conditions on temperature. Only rain episodes when visibility decreased below $1000 \mathrm{~m}$ (at least for part of the time) were considered rain with fog.

Based on the PWD data, the fog/freezing fog/rain with fog episodes were determined if the duration of the episode was longer than one hour, similar to the study by Zíková et al. (2020). For some cases, the temperature during the fog episode decreased below $0{ }^{\circ} \mathrm{C}$ and was coded as freezing fog. If the duration of the temperature decrease was not longer than one hour, the fog episode was not divided; thus, for a minority of data points, fog could be coded at subzero temperatures (Fig. 1). Even for freezing fog, however, the temperature did 

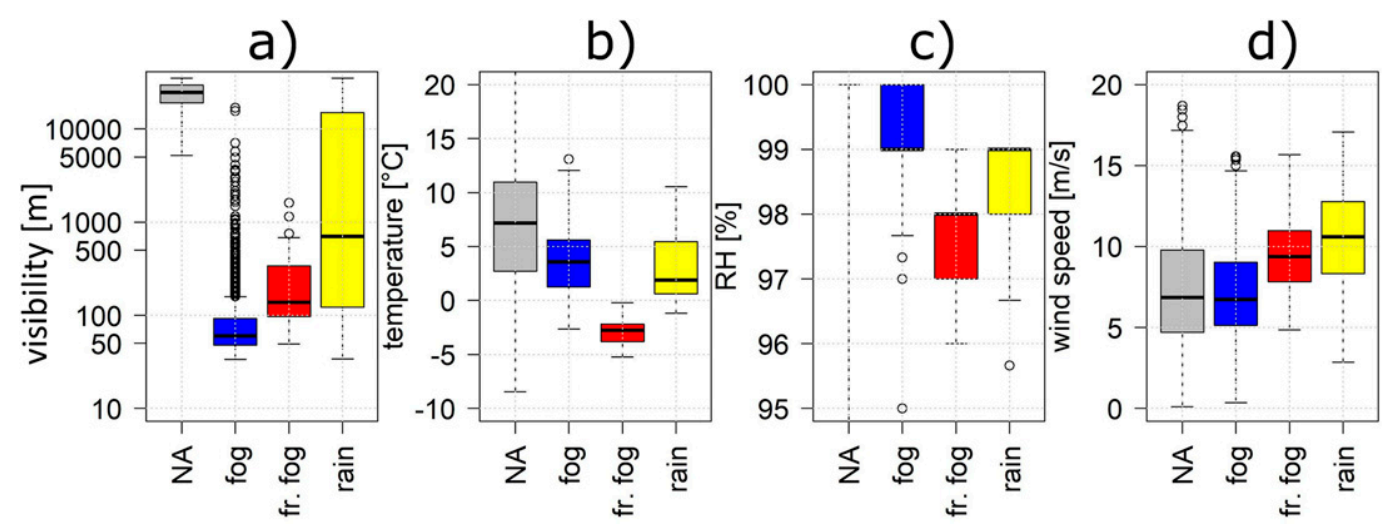

FIG. 1. Boxplot of (a) visibility, (b) temperature, (c) relative humidity, and (d) wind speed measured during individual phenomena.

not decrease below $-5^{\circ} \mathrm{C}$ (Fig. 1); thus, no ice crystals were expected.

\section{2) ATMOSPHERIC AEROSOL MEASUREMENTS}

For the aerosol concentrations, a set of aerosol spectrometers was used to obtain information on the particle number size distribution (PNSD) from $15 \mathrm{~nm}$ to $2.5 \mu \mathrm{m}$. The sampling program was the same as in the previous work (Zíková et al. 2020); therefore, only briefly: aerosols were sampled by two inlets, a $\mathrm{PM}_{2.5}$ and a heated whole air inlet (WAI), placed approximately $60 \mathrm{~cm}$ apart. Both inlets were attached to diffusion dryers with silica gel, creating low levels of humidity in the sampling lines; the mean relative humidity was $8.3 \%$ over the entire measurement. The two sampling lines were switched by a switching valve bringing the sample to a total condensation particle counter (CPC, 3010, TSI, United States), aerodynamic particle sizer (APS, 3021, TSI, United States), scanning mobility particle sizer (SMPS, consisting of an EC 3080 with a DMA 3081 and CPC 3775, all TSI, United States), and temperature and humidity sensors.

The switching system was synchronized with SMPS and APS samples so that after each switch, 1 min was left to flush the sampling line before both SMPS and APS started sampling (APS scan $210 \mathrm{~s}$, SMPS $180 \mathrm{~s}$ upscan and $30 \mathrm{~s}$ downscan). The flushing time was calculated to be over 10 times the delay time and confirmed experimentally by tests with a HEPA filter instead of one of the inlets. This test was performed periodically (once a week) to check the tightness of the sampling lines.

Similar to the study by Zíková et al. (2020), from the difference in PNSD measured by WAI and $\mathrm{PM}_{2.5}$, which measured all particles and interstitial particles only, respectively, activated PNSD (aPNSD) was calculated. This approach should be able to sample a majority of cloud droplets (Henning et al. 2002), although no additional instrumentation, such as FSSP or PVM, was available for a collocation measurement. During periods with no phenomena, the concentrations measured by the WAI and $\mathrm{PM}_{2.5}$ inlets should be identical, and the aPNSD should be zero. Due to the high variability in aerosol concentrations, however, some bins in the individual
aPNSD may be positive/negative (concentrations measured by the $\mathrm{PM}_{2.5}$ inlet were lower/higher than those measured by the WAI inlet), typically at sizes below $50 \mathrm{~nm}$. Similar effects were also observed in the case of low concentrations of activated particles. These negative values were only a measurement artifact and do not have any physical meaning; they may be replaced by zero values or kept in the dataset as a variability indicator.

\section{c. Activated fraction calculation}

The activated fraction (AF) was estimated as the ratio of activated particles to all particles available [i.e., $\left(\mathrm{WAI}-\mathrm{PM}_{2.5}\right)$ /WAI for each size bin (Asmi et al. 2012)]. The AF was fitted with a sigmoidal function to estimate the $D_{50}$ parameter, i.e., the diameter of particles out of which $50 \%$ are activated. The $D_{50}$ parameter can be used instead of the critical diameter $D_{c}$ (e.g., Paramonov et al. 2015). In this work, the 50\% variant of the critical diameter was used, as it does not expect an internally mixed aerosol as the minimum value $D_{c}$ version. For a clear distinguishing, the $D_{50}$ mark was used instead of $D_{c}$, similarly to, e.g., Verheggen et al. (2007).

From the AF function, the $D_{25}$ and $D_{75}$ values were also computed (i.e., diameter of particles out of which $25 \%$ and $75 \%$ are activated, respectively). To describe the variability in the activation process, $D_{\mathrm{IQR}}$ was calculated as the difference between $D_{75}$ and $D_{25}$; the smaller the $D_{\mathrm{IQR}}$ was, the steeper the function, and the process was expected to be more homogeneous (the aerosol population was expected to be internally well mixed).

\section{d. Data coverage}

The dataset consists of four measurement campaigns, each of which was at least 6 weeks long, taking place in spring and autumn months. An overview of the four campaigns, with the total measurement duration and number of samples, is shown in Table 1.

The measurement frequency of aerosol spectrometers was $5 \mathrm{~min}$, while the total CPC was measured every $5 \mathrm{~s}$ to describe the variability and/or changes in the concentrations below the time resolution of the spectrometers. The measurement was 
TABLE 1. Dates and duration of the four measurement campaigns, with number of fog episodes—covering fog and fog with rain episodes - and freezing fog episodes (in parentheses) and corresponding number of 10-min PNSD available. The sums of the phenomena contribution do not reach $100 \%$ as also other phenomena, not covered in this paper (e.g., rain showers, snow etc.), were recorded during the measurement period.

\begin{tabular}{|c|c|c|c|c|c|}
\hline No. & Dates & Duration (days) & Fog episodes (freezing fog) & PNSD & Fog PNSD \\
\hline I & 2 Nov 2018-14 Dec 2018 & 42 & $12(7)$ & 4894 & $1729(233)$ \\
\hline II & 21 Mar 2019-3 May 2019 & 43 & $6(2)$ & 4132 & $168(39)$ \\
\hline III & 14 Oct 2019-29 Nov 2019 & 46 & $22(4)$ & 4648 & $2023(0)$ \\
\hline IV & 5 Mar 2020-30 Apr 2020 & 56 & $3(1)$ & 1373 & $131(0)$ \\
\hline Total & & 187 & $43(14)$ & 15047 & $4051(272)$ \\
\hline
\end{tabular}

switched every $5 \mathrm{~min}$ between the $\mathrm{PM}_{2.5}$ and WAI inlets, resulting in complete information every $10 \mathrm{~min}$.

The original time resolution, i.e., $10 \mathrm{~min}$, was kept to observe the variability and changes. For some analyses, the hourly medians were calculated to have more robust data, and the resulting PNSD was smoother. The resulting dataset consists of $590 \mathrm{~h}$ of fog/freezing fog/rain with fog data, providing a strong statistical base for the description of the observed relationships.

In total, in 187 days of measurements, 43 episodes of fog, 14 episodes of freezing fog, and 31 episodes with vertical hydrometeors (rain and/or snow) were recorded. As an episode, observations of the given meteorological phenomena with at least one hour of duration were considered. During some of the episodes, however, aerosol instrumentation was not working; therefore, the resulting number of episodes with available data was lower (Table 1). Generally, both springs were dry, and most of the dataset thus originated in the autumn months, with a twice higher number of episodes and longer duration.

As the dependence of the activation on the preceding atmospheric processes was found, the dataset was subsetted into the episodes that were preceded only with periods without any phenomena observed. This subset consisted of 15 fog episodes, six episodes of freezing fog, and 19 episodes of rain.

\section{e. LWC and visibility}

From the visibility data (PWD52, Vaisala, Finland), the liquid water content (LWC) was calculated based on an empirical formula (Fišák et al. 2006):

$$
\mathrm{LWC}=0.0152(\mathrm{VIS})^{-0.8582}
$$

where LWC is in $\mathrm{g} \mathrm{m}^{-3}$ and VIS is visibility in kilometers. The regression equation originated from the collocation measurement using a particle volume monitor (PVM-100, Gerber Scientific, United States) several years ago when the PVM was available at the observatory.

\section{f. Effective radius}

From the LWC and the concentration of particles in the accumulation mode, i.e., particles larger than $100 \mathrm{~nm}$, it is possible to estimate the effective droplet radius $R_{\text {eff }}(\mu \mathrm{m})$, describing the mean radius of cloud droplet size distribution (Henning et al. 2002):

$$
R_{\text {eff }}=\sqrt[3]{\frac{\mathrm{LWC} \times 10^{9}}{\rho_{w} N_{\mathrm{ACT}>100 \mathrm{~nm}}} \frac{3}{4 \pi}},
$$

where $\rho_{w}$ is the water density $\left(\mathrm{kg} \mathrm{m}^{-3}\right) ; N_{\mathrm{ACT}}$ is the concentration of all activated particles larger than $100 \mathrm{~nm}$, as measured by the difference between the WAI and $\mathrm{PM}_{2.5}$ inlets (in $\mathrm{cm}^{-3}$ ); and LWC is in grams per cubic meter $\left(\mathrm{g} \mathrm{m}^{-3}\right)$. The effective droplet radius $R_{\text {eff }}$ is used for cloud depth calculations and radiative forcing estimates (Hsieh et al. 2009). Since in our calculations, the LWC was calculated from visibility without any upper limit and no lower limit for LWC was applied, higher variability in calculated $R_{\text {eff }}$ compared with measured $R_{\text {eff }}$ is expected.

\section{g. Cluster analysis}

For each of the 187 days of measurement, 72-h backward trajectories were calculated using the Hybrid Single-Particle Lagrangian Integrated Trajectory (HYSPLIT) model (Rolph et al. 2017; Stein et al. 2015) with the starting position at $200 \mathrm{~m}$ AGL and Global Data Assimilation System (GDAS) archive information at a resolution of $1^{\circ} \times 1^{\circ}$ as input data. The calculations were initialized every $6 \mathrm{~h}$ at $0100,0700,1300$, and 1900 UTC, i.e., 0000, 0600, 1200, and 1800 local time, resulting in 740 trajectories in total. The trajectories were further clustered within the HYSPLIT4 application based on the total spatial variance. The same cluster number was assigned to all aerosol samples obtained during the $6 \mathrm{~h}$ after.

\section{Results}

\section{a. Meteorological variables during campaigns}

First, the values of meteorological variables during the episodes were compared with the values during periods when no meteorological phenomena were coded (code 00). Of course, the highest visibility was measured without any phenomena (statistically significant difference at the 0.05 level, Fig. 1a). Compared with rain, however, the difference is not statistically significant-during rain episodes, the visibility sometimes exceeded $1000 \mathrm{~m}$.

Without any phenomenon, higher temperatures were measured (Fig. 1b), as most sunny days fell into this category. For any hydrometeor, the median temperature was at least three degrees lower. Temperature of course did differ during fog and freezing fog (fr. fog); while the median was over zero for fog, it was below zero for freezing fog (Fig. 1b). Otherwise, from the point of view of temperature, the temperature was comparable for fog and rain.

Temperature could also be connected with global radiation, which could have affected aerosol properties through 


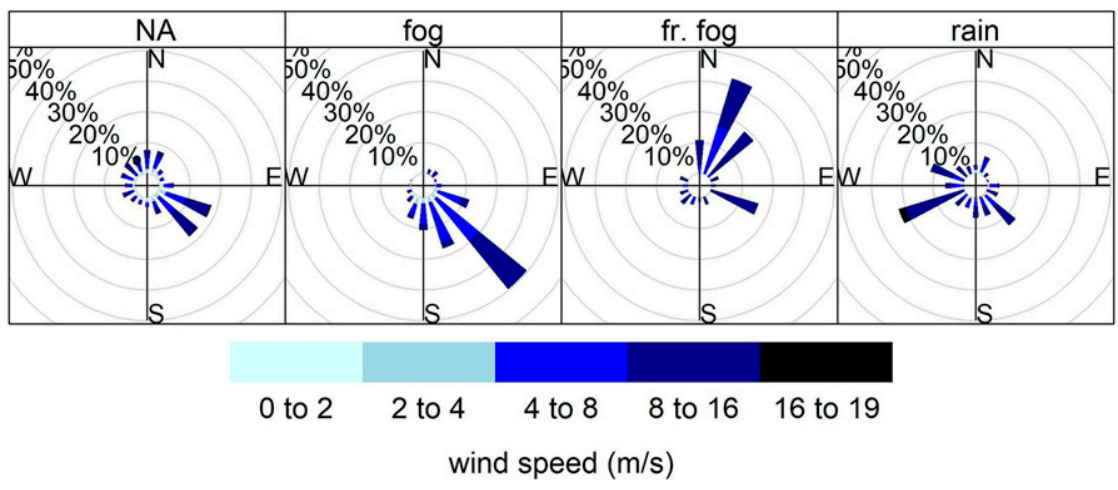

FIG. 2. Frequency of wind speed counts by wind direction for individual hydrometeors compared with no phenomena observed (NA).

photochemistry. If the daily cycle of the $D_{50}$ position was plotted (Fig. S1 in the online supplemental material), however, no diurnal pattern was observed, similar to Paramonov et al. (2015) at low supersaturations $(0.1 \%)$, and thus, the activation did not seem to be strongly affected by photochemistry (which is generally low during fog events).

Relative humidity without any phenomena observed at the observatory reached $70 \%$ (median value, interquartile range, IQR $52 \%-87 \%$, Fig. 1c), while with the hydrometeors, the median values reached $99 \%$ for fog and rain and $98 \%$ for freezing fog. The accuracy of the RH measurements $( \pm 3 \%)$ limits the possibility of further conclusions based on the $\mathrm{RH}$ values.

The wind speed during the presence of hydrometeors (Fig. 1d) was higher than the mean wind speed during the entire campaign $\left(7.1 \mathrm{~m} \mathrm{~s}^{-1}\right)$ and higher than that without any phenomenon observed $\left(6.9 \mathrm{~m} \mathrm{~s}^{-1}\right.$, statistically significant difference). The only exception was fog, with a mean wind speed lower $\left(6.7 \mathrm{~m} \mathrm{~s}^{-1}\right)$ than that during any other phenomenon and comparable to no phenomena conditions. For freezing fog and rain, no statistically significant difference in wind speed was found, with median values varying from 9.4 to $10.6 \mathrm{~m} \mathrm{~s}^{-1}$ (Fig. 1d).

From the analysis of wind speed together with wind direction for individual phenomena, the differences in the meteorological conditions further increased. The prevailing wind direction at the observatory during the campaigns was from southeast to east-southeast (together $29.9 \%$ of occurrence, Fig. S2), similar to episodes without any phenomena observed (Fig. 2). The prevalence of the southeast direction was also visible during fog episodes. For freezing fog, the north-northeast direction was prevalent, while rain occurred with completely different wind directions; rain was connected to the northwest or southwest direction, i.e., westerlies typical at most stations in Czechia (Tolasz et al. 2007). The difference in the wind roses suggests that different air masses had reached the observatory, resulting in different hydrometeors being observed.

Thus, the back trajectories describing the air mass origin were clustered using the HYSPLIT model into seven clusters (Fig. 3a) and compared with the hydrometeor episodes.

The most frequent cluster during the measurement campaigns was cluster $4 \mathrm{a}$ ( $29 \%$ of the time, Table S1), i.e., slow air masses remaining for a long time over central Europe. Similar behavior was also connected to cluster $3 \mathrm{a}$, which had the highest fog occurrence. In contrast, the two least frequent air masses were in clusters $6 a$ and $7 \mathrm{a}$ ( $5 \%$ of the time). Some maritime influence can be observed in clusters $7 \mathrm{a}$ and $2 \mathrm{a}$. Cluster 5a, consisting of continental trajectories from the northeast, was slightly special.

For most clusters, for more than $50 \%$ of the time, no phenomena were observed; for cluster $6 \mathrm{a}$, the phenomenon-free frequency reached $82 \%$, and it was $74 \%$ and $76 \%$ for clusters 4a and 7a (Table S1). Thus, clustering was also performed for a subset of trajectories based on the occurrence of phenomena. Only the trajectories with at least one phenomenon observation recorded during the 6-h period between trajectories were considered (262 out of 740) and clustered again. In the subset, four clusters were identified (Figs. 3b and S3).

In the subset clusters (denoted as "b," not to be mistaken with the original clusters), a similar frequency of occurrence was found for clusters $2 b$ and $3 b$ (Table 2), i.e., western continental air mass and very slow circulating continental air mass over Central Europe. The other two clusters were formed by maritime air (1b) and air masses with southern trajectories (4b), bringing warm air to the Central Europe region.

From a meteorological point of view, the clusters may have been connected with different conditions (for most variables, the conditions were different in various clusters as tested by Dunn's test). During cluster $1 \mathrm{~b}$ connected to fast maritime air masses, the highest wind speeds were recorded (Fig. 4d), the visibility was the least influenced, and the highest occurrence of rain episodes was observed. This cluster could have been connected to cyclonic conditions with atmospheric front passages. Air masses in cluster $2 \mathrm{~b}$ were formed by air without a strong maritime influence in the last three days. The RH and temperatures were comparable to $1 b$; however, the frequency of fog occurrence was higher, and thus, the overall visibility was lower (median $352 \mathrm{~m}$, Fig. 4c). Cluster 3b consisted of cold continental air from the east, connected to anticyclonic conditions over Central Europe (with the center of the anticyclone to the east of Czechia). Cluster $4 \mathrm{~b}$ consisted of warm air masses coming from the south; as most measurements were performed in the autumn, the warm air could have resulted in stable or 

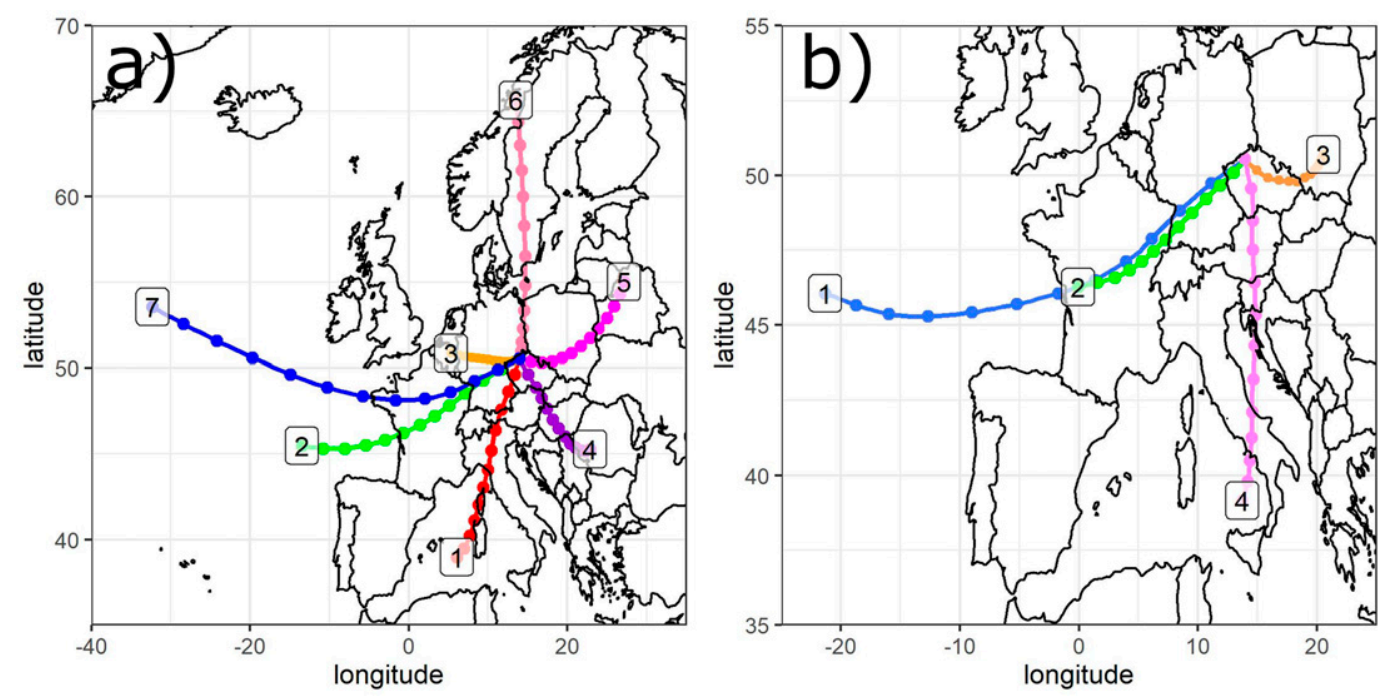

FIG. 3. Geographical location of the means of the clusters during (a) ar measurement campaigns and (b) only during periods with any phenomena observed.

inversion conditions above the Czech Basin, with subinversion clouds recorded at the station (median visibility $61 \mathrm{~m}$, Fig. 4c).

\section{b. Activated and interstitial PNSD}

Variability during the activation process was observed both in interstitial particles sampled with the $\mathrm{PM}_{2.5}$ inlet and in the activated particles calculated as the difference between concentrations measured by the WAI and $\mathrm{PM}_{2.5}$ inlets (Fig. 5).

The number of interstitial particles measured during any of the phenomena was lower at all sizes in comparison to episodes without any phenomena observed (Fig. 5a). During fog events, the mode position of the interstitial PNSD was observed at larger particles, peaking at 67 and $97 \mathrm{~nm}$ for fog and freezing fog, respectively, compared with $39 \mathrm{~nm}$ during periods without any phenomena observed (Table S2). The position of the mode agrees well with the interstitial particle mode position of $65 \mathrm{~nm}$ reported during cloud episodes at Jungfraujoch (JFJ), Switzerland (Henning et al. 2002). A similar difference in interstitial PNSD during the presence of

TABLE 2. Number of trajectories in individual clusters from Fig. $3 b$ and number of available PNSDs for each cluster and phenomena. NA denotes PNSD without any meteorological phenomena observed. Values in parentheses denote the percentage of the given value from all observed PNSD/trajectories in the given cluster.

\begin{tabular}{lcccc}
\hline \hline \multicolumn{1}{c}{ Cluster No. } & 1 & 2 & 3 & 4 \\
\hline No. of trajectories & $35(13)$ & $100(38)$ & $94(36)$ & $33(13)$ \\
PNSD & 1246 & 3387 & 3213 & 1153 \\
Fog & $423(34)$ & $1464(43)$ & $1190(37)$ & $962(83)$ \\
Freezing fog & - & $31(1)$ & $241(8)$ & - \\
Rain & $298(24)$ & $169(4)$ & $144(4)$ & - \\
NA & $440(35)$ & $1170(35)$ & $677(21)$ & $109(9)$ \\
\hline
\end{tabular}

fog versus during the absence of fog was also observed by Zíková and Zdimal (2016) at a rural station in the Czech Republic and may have been connected to different conditions (e.g., air masses) during fog rather than to a change in the PNSD during the fog episode. The presence of rain, however, did not change the mode position and only decreased the concentration. This is in accordance with similar wind speeds and directions during rain and no episodes (and thus, similar air masses), while the wind speeds and directions were different during fog events (Fig. 2). If the total concentrations are considered (Fig. S4), the decrease in total concentration of interstitial particles is clearly visible for all phenomena and statistically significant (at the 0.05 level).

If the aPNSDs are considered, most activated particles were larger than $100 \mathrm{~nm}$, peaking at over $200 \mathrm{~nm}$ (Fig. 5b, Table S2). The aPNSD for fog and freezing fog had similar shapes (both from a mode position and concentration point of view). During episodes with rain and fog together, the aPNSD mode position was comparable to fog (peaking at $180 \mathrm{vs} 240 \mathrm{~nm}$ for fog). In terms of concentrations of activated particles, much lower concentration were measured during rain and fog than during fog episodes ( $80 \mathrm{vs} 500 \mathrm{~cm}^{-3}$ ), suggesting that the activation process was not as successful during rain as it is during fog. During rainout, part of the humidity was removed from the cloud, and lower $S$ values were reached, resulting in less effective activation.

The PNSD and aPNSD were not stable during the episodes - both mode position and peak concentration varied with time and other variables. Division of the aPNSD according to clustering confirms the results of the previous campaigns; the maritime cluster with the highest wind speed (cluster 1b) had an aPNSD shifted to smaller sizes (Fig. S5b). It is assumed that the difference in the aPNSD in cluster $1 \mathrm{~b}$ may have been connected to the disruption of the inversion 

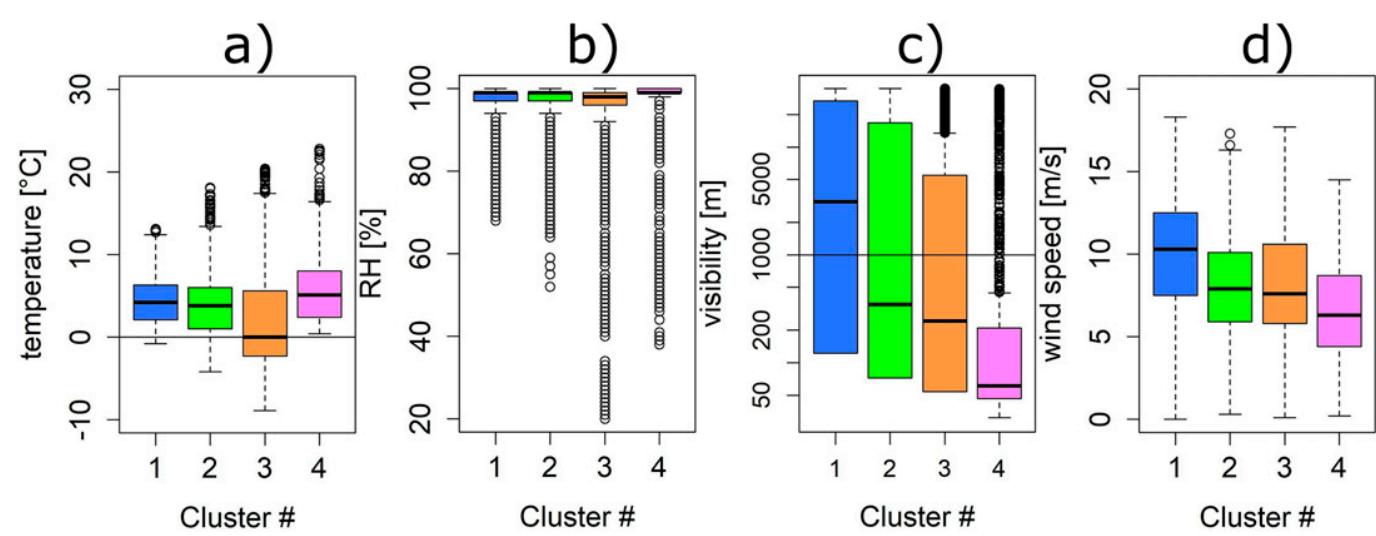

FIG. 4. Boxplots of (a) temperature, (b) relative humidity, (c) visibility, and (d) wind speed in individual clusters. Color coding of the clusters is the same as in Fig. $3 \mathrm{~b}$.

layer with a cloud layer formed by the top of the layer. Once the inversion layer was disrupted-due to an air mass with high wind speed-the activation process was changed as well, thanks to the air mass of maritime origin replacing the stable and aged air mass that was present before the disruption.

The dependence of the activated particles on the air masses was also confirmed with the dependence on the wind speed and direction (Fig. S6). For no phenomenon episodes, no directional dependence was found for the total number of activated particles, and a strong preference for west to northwest directions was found for fog and freezing fog episodes. The highest numbers of activated particles during fog were observed during times of southwest-northwest wind directions with wind speeds over $10 \mathrm{~m} \mathrm{~s}^{-1}$. For freezing fog, the same conditions applied, with additional high concentrations observed during very low

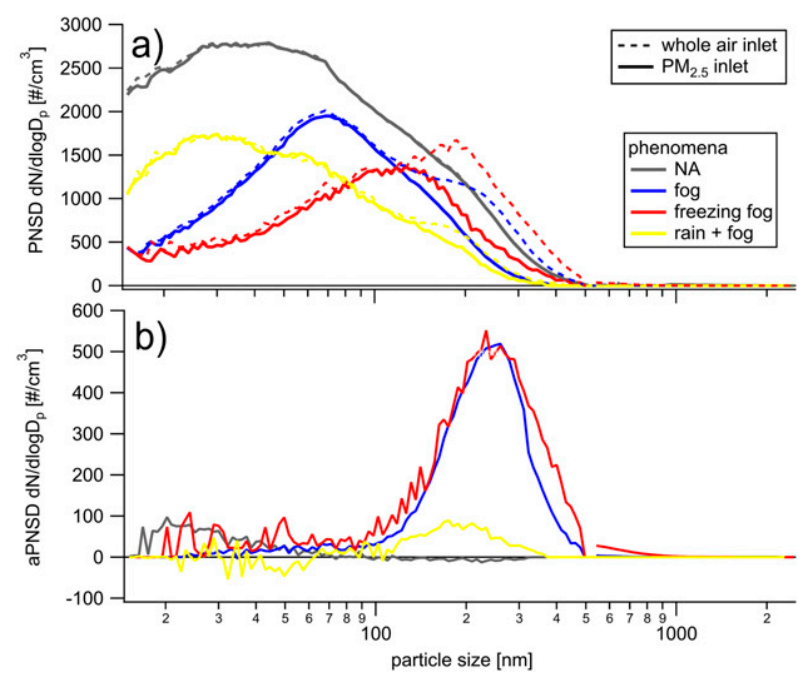

FIG. 5. (a) Medians of PNSD from the WAI and $\mathrm{PM}_{2.5}$ inlets (interstitial particles) and (b) activated particles for fog, freezing fog, and rain with fog, in comparison with no phenomena episodes (denoted as NA in the plot). wind speeds (Fig. S6). During rain with fog, some activated particles were also observed during fast westerlies, but with concentrations well below those observed during the fog or freezing fog episodes.

\section{c. Activated fraction}

The activated fraction (AF) calculated from all data, divided only into individual hydrometeor types, did not reveal any differences between fog and freezing fog, with both curves almost overlapping each other (Fig. S7). The AF during rain with fog was similar to that during fog episodes but less smooth. Thus, the data were analyzed with respect to additional variables.

If the origin of the air masses, based on the back-trajectory analysis, was considered, more information on the process could be deduced. The results based on a dataset twice as long as that in Zíková et al. (2020) are basically identical to those in the previous study: for fog, the AF was not highly variable between clusters, with the exception of cluster $1 \mathrm{~b}$, which showed a shift of the curve to smaller particles (Fig. S8, top). During freezing fog observed only in clusters $2 b$ and $3 b$, the $D_{50}$ values did not differ between clusters, varying only between $227 \mathrm{~nm}$ for cluster $2 \mathrm{~b}$ and $262 \mathrm{~nm}$ for $3 \mathrm{~b}$ (Table S3); the total activated fraction (the asymptote the curve reaches for the largest particles) was approximately $90 \%$ for all clusters. For rain with fog episodes observed in clusters $1 b$ and $2 b$, the variability in the AF between clusters was stronger (Fig. S8, bottom).

The difference between the clusters may be explained by either various meteorological conditions and/or various chemical compositions of the aerosols. As the activated fraction did not reach 1 , the aerosol is expected to have been externally mixed or subjected to changes in supersaturation (Verheggen et al. 2007) due to fluctuation-influenced regime (Shawon et al. 2021). In the different clusters, air masses with different chemical compositions were sampled at the location; however, the difference in the AF was not strong. Thus, the $D_{50}$ value (a diameter corresponding to half of the asymptote height) was used as a metric describing the activation process and compared with other variables to obtain more information on the difference in 

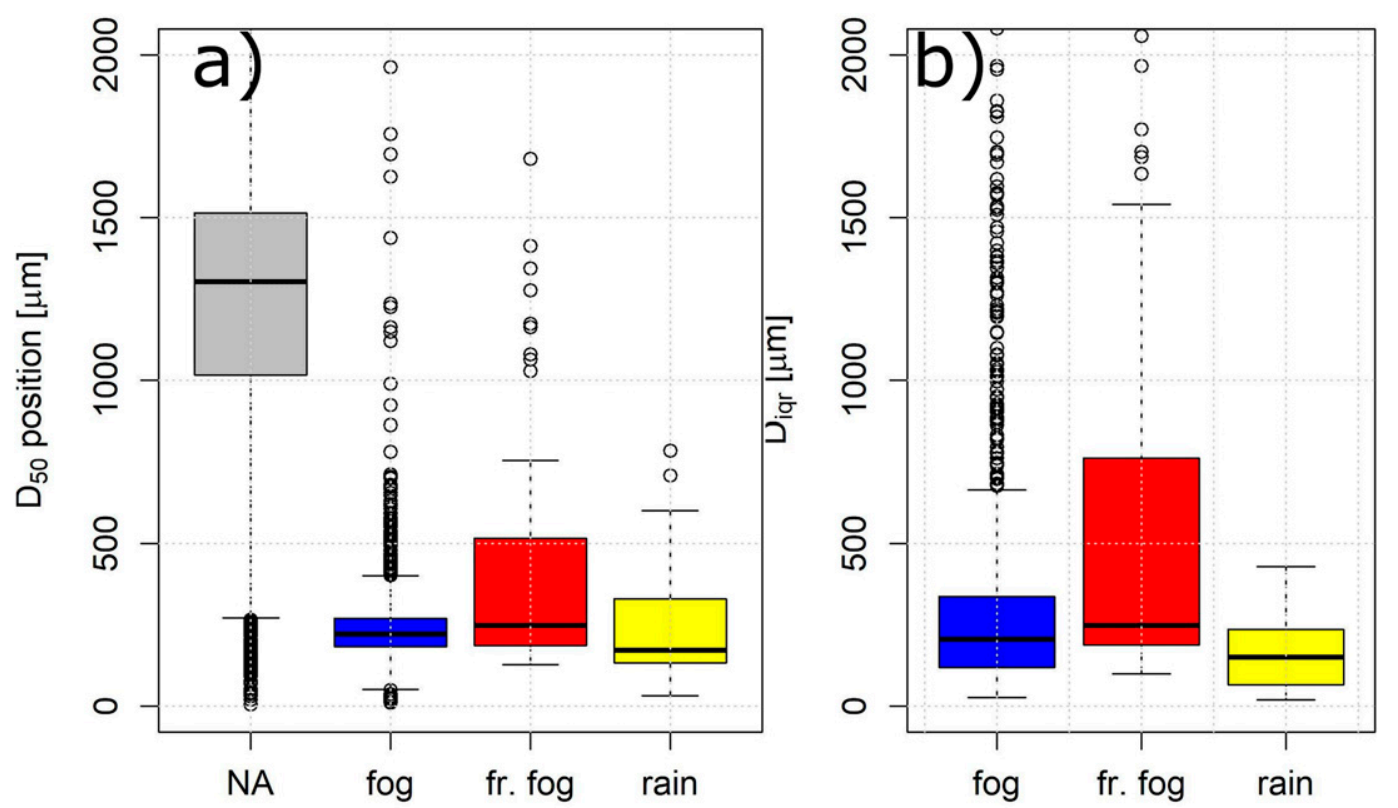

FIG. 6. Boxplots of (a) the $D_{50}$ position and (b) $D_{\mathrm{IQR}}$ during individual phenomena.

activation between hydrometeors and in clusters, with a focus on meteorological conditions (influencing supersaturation) rather than chemical composition.

\section{1) $D_{50}$ POSITION}

For the entire campaign, i.e., 187 days of data, the sizedependent activated fractions were calculated every $10 \mathrm{~min}$; the 10-min data were used for median calculation every $30 \mathrm{~min}$. Averaging was used to smooth the data, and the smoothed data were fitted with a sigmoidal function when possible-for episodes without any phenomenon, the fitting process was often terminated due to missing data. These data points were replaced with NA. From the fitting, all available $D_{50}$ values were compiled and compared with 30-min averages of meteorological variables.

During nonphenomenon periods, $D_{50}$ calculated as a check of the method showed values over $1 \mu \mathrm{m}$ (Figs. 6a and S7) - connected to the inlet cutoff and connected uncertainties. It of course differed from the $D_{50}$ position during fog, freezing fog, or rain with fog episodes (Fig. 6a). The differences between fog and freezing fog (medians $221 \mathrm{vs} 248 \mathrm{~nm}$ ), however, are not statistically significant. What differs during fog and freezing fog, however, is the $D_{\mathrm{IQR}}$ (Fig. 6b). During freezing fog, a larger $D_{\mathrm{IQR}}$ value in comparison with fog events (Fig. 6b) was found. This may have been a result of higher variability in supersaturation, a smaller degree of internal mixing of aerosols, or multiple factors influencing the activated fraction simultaneously (Verheggen et al. 2007). While both fog and freezing fog were sampled in the same air masses, no strong difference in chemical composition was expected; the variability in supersaturation may have played a role due to its connection with temperature (a variable dividing fog and freezing fog).
If the $D_{50}$ position during fog/freezing fog/rain with fog is compared with the various meteorological variables, some general patterns can be seen. With increasing relative humidity, the $D_{50}$ position decreased (Fig. 7a) as smaller particles could be activated-when the humidity reached $98 \%$, the $D_{50}$ median position decreased below $300 \mathrm{~nm}$, a value typical for the mode in aPNSD (Fig. 5b), and continued to decrease to $190 \mathrm{~nm}$ for $100 \% \mathrm{RH}$. The boxplot for the highest RH shows a very narrow interquartile range (IQR, ranging only from 158 to $233 \mathrm{~nm}$ for over 300 samples, not shown here), confirming rather homogeneous conditions at the observatory leading to fog or low cloudiness formation. This is supported by the analysis based on air mass origin (Fig. 7a) - in the $100 \% \mathrm{RH}$ group, no statistically significant differences were found in $D_{50}$ positions in individual clusters, with medians varying only between 175 and $195 \mathrm{~nm}$. This dependence of RH and $D_{50}$ agrees with the theory by Prabhakaran et al. (2020) regarding regimes of activation changing with $\mathrm{RH}$. At $100 \% \mathrm{RH}$, the meandominated supersaturation regime is expected, with most aerosol population exposed to a similar supersaturation. With decreasing $\mathrm{RH}$, the importance of supersaturation fluctuations would increase, moving to a fluctuation-influenced regime. The fluctuations in supersaturation would result in higher scatter in activation and $D_{50}$ (Fig. 7a). Thus, the mean relative humidity does not seem to be a sufficient variable to describe the individual events, and an estimation of the supersaturation fluctuations would be better.

In the dependence of $D_{50}$ on the temperature during fog/freezing fog/rain with fog episodes, no relationship between $D_{50}$ and temperature was observed in the temperature interval between $0^{\circ}$ and $+6^{\circ} \mathrm{C}$ (Fig. 7b). The median varies only between 190 and $231 \mathrm{~nm}$ (between $-2^{\circ}$ and $0^{\circ} \mathrm{C}$, respectively, not shown). The small variability in the $D_{50}$ position is clearly visible also if 

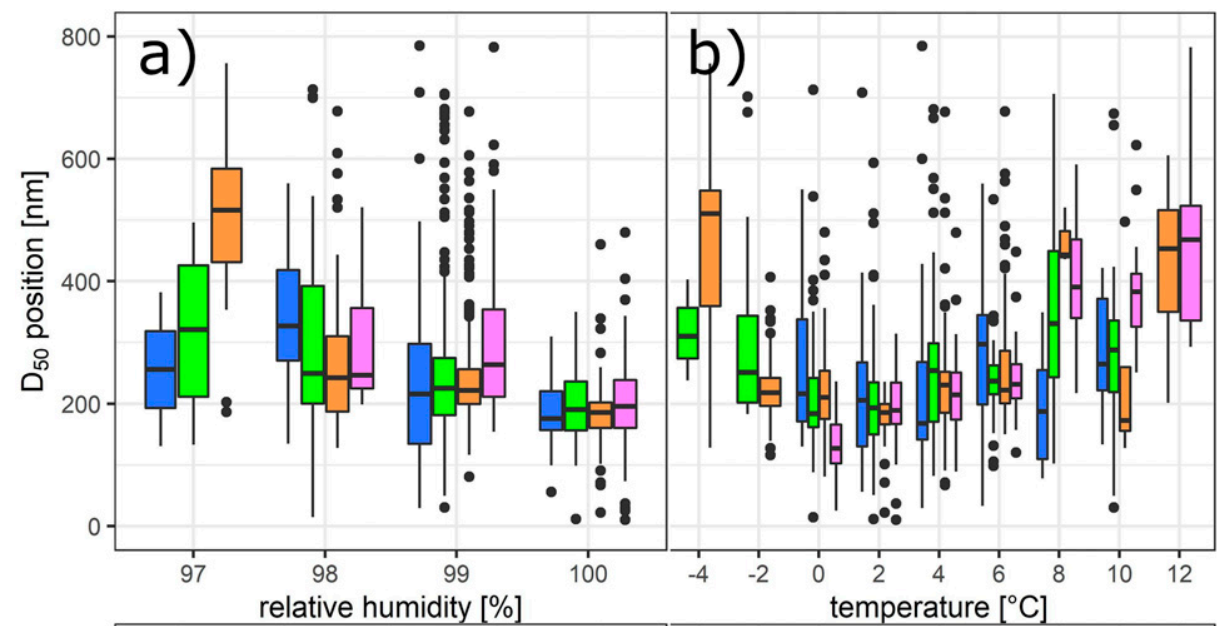

cluster \#

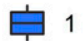

它 2

官 3

官 4

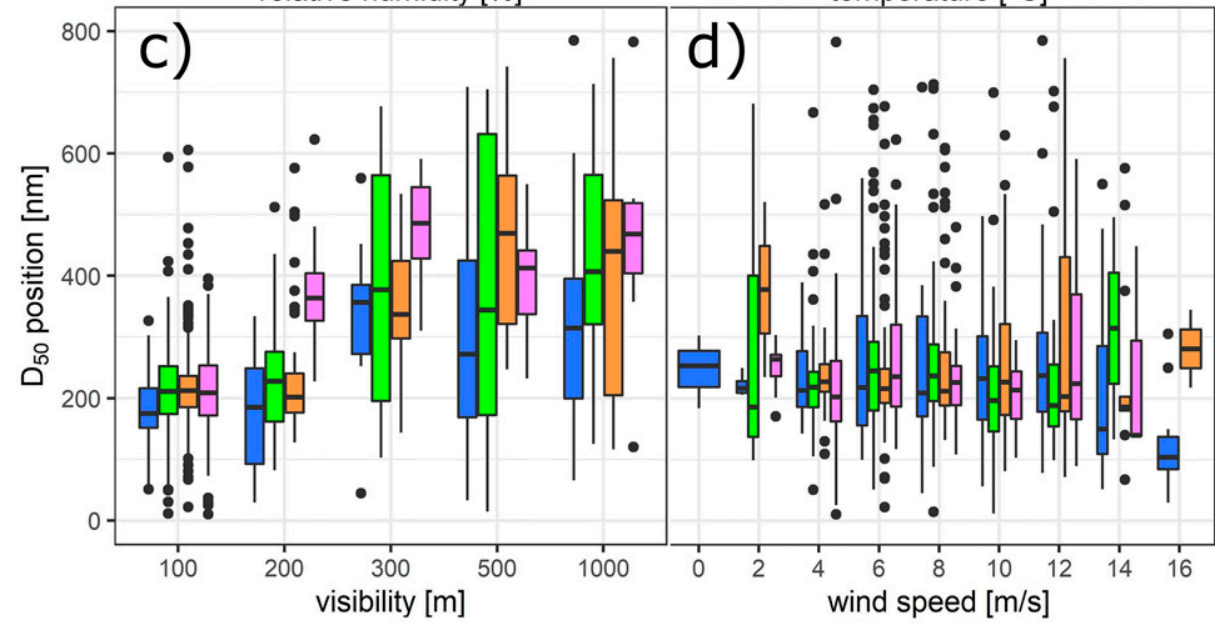

cluster \#

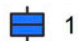

官 2

它 3

官 4

FIG. 7. Boxplots of dependence of the $D_{50}$ position during fog/freezing fog/rain with fog on (a) relative humidity, (b) temperature, (c) visibility classes (number on $x$ axis denotes maximal visibility in a given class), and (d) wind speed, in relation to air mass clusters (denoted by the same colors as in Fig. 3b).

the air mass origin is considered, since the $D_{50}$ at $200 \mathrm{~nm}$ was observed in all clusters (Fig. 7b).

For temperatures higher than $+6^{\circ} \mathrm{C}$ and below $-2^{\circ} \mathrm{C}$, the $D_{50}$ position increased, suggesting activation of particles mostly larger than $300 \mathrm{~nm}$. The results may have been influenced by the smaller number of data points in this temperature interval (usually less than 20 per boxplot in Fig. 7b), and/or the conditions may have been connected to higher fluctuations in humidity (mainly for temperatures over $+8^{\circ} \mathrm{C}$ ) that would have required higher absolute humidity to reach saturation. For the temperature range below $0^{\circ} \mathrm{C}$, a decrease in the activated fraction with decreasing temperatures was also observed by Verheggen et al. (2007) due to the lower absolute water vapor concentration necessary for (super)saturation.

From the visibility point of view, the main difference was for visibilities below and over $200 \mathrm{~m}$ (Fig. 7c). Both the $<100$ - and 100-200-m groups had medians of $D_{50}$ below $250 \mathrm{~nm}$, and the visibility values differed from the three groups with visibilities $300-1000 \mathrm{~m}$. The only difference was for cluster $4 \mathrm{~b}$ with over $76 \%$ of data points in the $<100-\mathrm{m}$ and thus the $100-200-\mathrm{m}$ group did not differ from the groups with higher visibilities. The very small scatter for the visibility class below $100 \mathrm{~m}$ for all clusters (IQR ranging only from 152 to $252 \mathrm{~nm}$ ) is surprising, mainly due to the highest number of observations in the class (814 out of 1104). This may have been connected to the small variability of subinversion clouds that the station is prone to, as in the dataset with visibilities below $100 \mathrm{~m}$, lower than average wind speeds were recorded (median $6.5 \mathrm{~m} \mathrm{~s}^{-1}$ ).

In the other three visibility classes $(200-300 \mathrm{~m}, 300-500 \mathrm{~m}$, and $500-1000 \mathrm{~m}$ ), not even the first quartile reached $D_{50}$ values below $250 \mathrm{~nm}$ for most clusters. With increasing visibility, a higher median $D_{50}$ was observed (380 nm in the 200-300-m class and $500 \mathrm{~nm}$ in the 500-1000-m class). Among the three classes, however, no significant difference was found (this may be connected to the relatively small number of observations in the classes, from 42 to 55 in the three groups).

For wind speeds below approximately $10 \mathrm{~m} \mathrm{~s}^{-1}$, most $D_{50}$ values were at approximately $200 \mathrm{~nm}$, and the activation was insensitive to wind speed, similar to Verheggen et al. (2007). During situations with wind speeds over $10 \mathrm{~m} \mathrm{~s}^{-1}$, the scatter of 
the $D_{50}$ values started to increase (Fig. $7 \mathrm{~d}$ ). With the higher wind speed, the higher importance of turbulence could be expected, leading to fluctuation-influenced activation that increased the heterogeneity in the observed $D_{50}$.

Higher turbulence cannot explain the smallest $D_{50}$ for cluster $1 \mathrm{~b}$ and wind speeds over $12 \mathrm{~m} \mathrm{~s}^{-1}$ (Fig. 7d). During times of smaller wind speeds, the $D_{50}$ position in cluster $1 \mathrm{~b}$ did not differ from other clusters; for wind speeds over $12 \mathrm{~m} \mathrm{~s}^{-1}$, the $D_{50}$ decreased from $230 \mathrm{~nm}$ to 149 and $103 \mathrm{~nm}$ (median values for 14 and $16 \mathrm{~m} \mathrm{~s}^{-1}$ ). The decrease in $D_{50}$ with increasing wind speed may have been connected to inversion layer disruption by fresh maritime air masses from cluster $1 \mathrm{~b}$, bringing more hydroscopic aerosol, or the higher wind speeds may have supported the activation by higher supersaturation by upslope winds, although this is typically not observed at the station during fog episodes.

If only the air mass origin had been taken into account for each phenomenon, based on Dunn's test, the $D_{50}$ position would have been comparable in all clusters for fog (Fig. 8a) with the exception of maritime cluster 1 b with a lower $D_{50}$ position. For freezing fog, no significant difference was found between clusters (Fig. 8b), similar to rain with fog (Fig. 8c). The clusters are made of highly dissimilar air masses (fresh maritime air in $1 \mathrm{~b}$ versus aged air circulating over central Europe in $3 \mathrm{~b}$ ); however, the $D_{50}$ at the station did not mimic the variability in air mass origin. Nor was the variance observed in the $D_{\text {IQR }}$ (Fig. 8 bottom); for fog, no significant difference was found between clusters (Fig. 8a), and the results were not conclusive for freezing fog and rain with fog. For freezing fog, a smaller $D_{\mathrm{IQR}}$ was found for cluster $2 \mathrm{~b}$ than for cluster $3 \mathrm{~b}$, and it was comparable for rain with fog (statistically insignificant difference).

\section{2) $D_{50} \mathrm{VS} \mathrm{LWC}$}

Another meteorological variable important for activation is LWC. The LWC calculated from visibility during individual phenomena was compared with the no phenomena episodes (Fig. 9a) and to other stations to describe the conditions at the observatory. The mean LWC of $0.15 \mathrm{~g} \mathrm{~m}^{-3}$ (median $0.17 \mathrm{~g} \mathrm{~m}^{-3}$ ) during fog was smaller but still comparable to cloud conditions reported at JFJ $-0.23 \mathrm{~g} \mathrm{~m}^{-3}$ (Henning et al. 2002). The LWC during freezing fog was even lower (median $0.10 \mathrm{~g} \mathrm{~m}^{-3}$, a statistically significant difference from fog).

If the LWC in individual air mass trajectory clusters was considered (independent of the phenomena observed), the difference in LWC between clusters was statistically significant (not shown). The lowest LWC was measured during cluster 1b, with $75 \%$ of the data below $0.1 \mathrm{~g} \mathrm{~m}^{-3}$. In contrast, during cluster $4 \mathrm{~b}$, almost $75 \%$ of the LWC was over $0.1 \mathrm{~g} \mathrm{~m}^{-3}$. The difference in LWC was connected with different frequencies of individual phenomena, namely, rain with fog, during which a lower LWC was observed (Fig. 9d).

If only fog episodes are considered, the lowest LWC remained in cluster $1 \mathrm{~b}$ (with a median over $0.1 \mathrm{~g} \mathrm{~m}^{-3}$, Fig. 9b), while no difference was found between clusters $3 \mathrm{~b}$ and $4 \mathrm{~b}$. Similarly, for freezing fog, no difference in LWC was found between clusters (Fig. 9c). For rain episodes, the dependence of LWC on clusters was significant, with western air masses

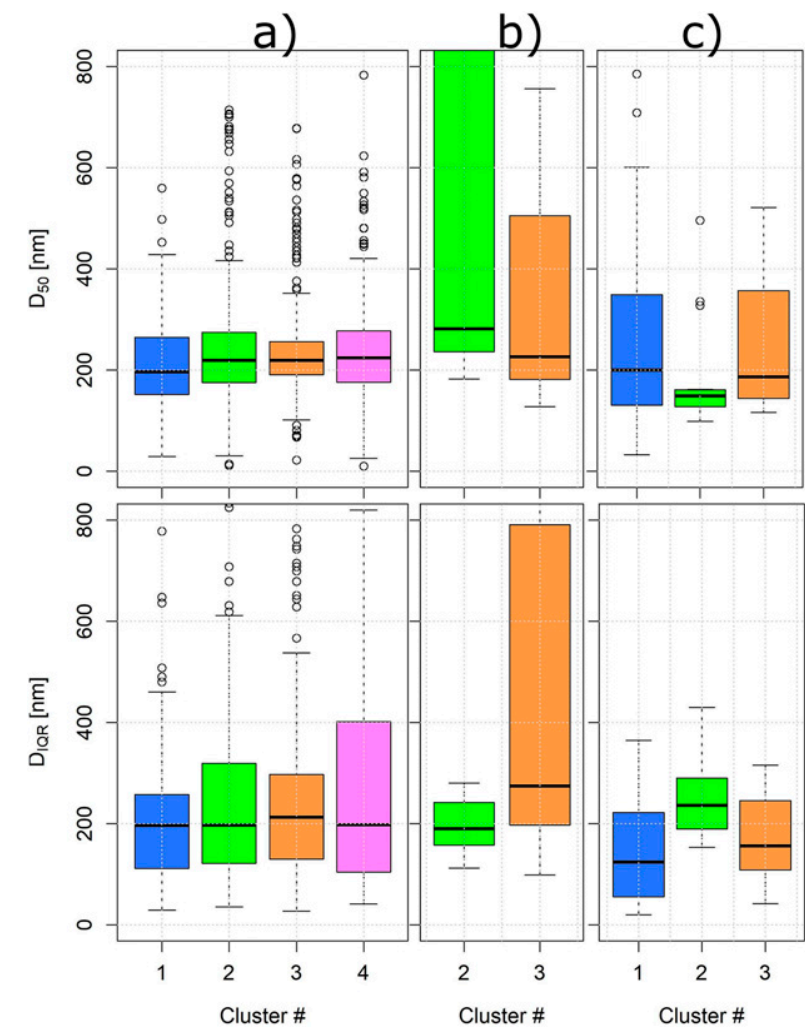

FIG. 8. Boxplots of the (top) $D_{50}$ position and (bottom) $D_{\mathrm{IQR}}$ during (a) fog, (b) freezing fog, and (c) rain with fog episodes in individual clusters.

(clusters $1 \mathrm{~b}$ and $2 \mathrm{~b}$ ) being connected with a one order of magnitude higher LWC than the continental air masses (3b, Fig. 9d).

Variability in LWC also translates into the variability in $D_{50}$ values. With increasing LWC, $D_{50}$ decreased at the beginning of the episode. Later in the episode (after approximately 4-6h), however, no such relationship was typically observed in the LWC and $D_{50}$ dependence, and during some episodes, $D_{50}$ varied by $80 \mathrm{~nm}$ with LWC being almost constant (Fig. 10a, episode 8 , for example). The same behavior also applied to freezing fog episodes, with LWCs lower than those during fog (Fig. 10b).

To describe a general behavior, boxplots of $D_{50}$ positions were calculated for LWC intervals from 0 to $0.3 \mathrm{~g} \mathrm{~m}^{-3}$ (Fig. 11). From the analysis, the decrease in the $D_{50}$ position can be estimated. From the linear regression of the medians from 0.02 to $0.10 \mathrm{~g} \mathrm{~m}^{-3}$, a decrease of $35 \mathrm{~nm}$ in the $D_{50}$ position was found for every $0.01 \mathrm{~g} \mathrm{~m}^{-3}$ increase in the LWC (Fig. 11a). From $0.10 \mathrm{~g} \mathrm{~m}^{-3} \mathrm{LWC}$ and higher, the $D_{50}$ medians did not vary much and only fluctuated at approximately $200 \mathrm{~nm}$ (mean $212 \pm 15 \mathrm{~nm}$ ). This constant behavior of $D_{50}$ with respect to LWC was also found by Henning et al. (2002), who reported a stable relationship for LWCs over $0.08 \mathrm{~g} \mathrm{~m}^{-3}$ and by Verheggen et al. (2007) for LWCs over $0.2 \mathrm{~g} \mathrm{~m}^{-3}$. Thus, for LWCs below $0.1 \mathrm{~g} \mathrm{~m}^{-3}$, in the LWC-limited regime, the LWC values and variables affecting the LWC-supersaturation, 

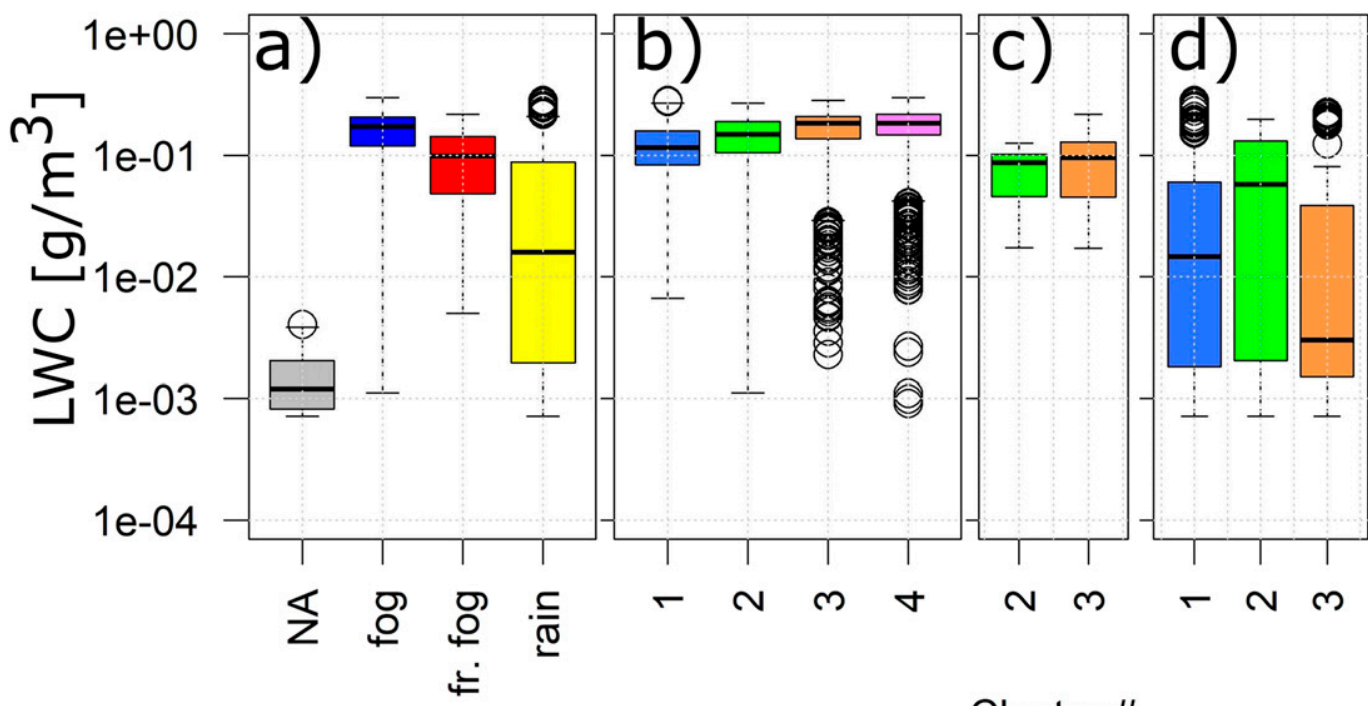

\section{Cluster \#}

FIG. 9. Boxplots of LWCs in relation to (a) individual phenomena and clusters with (b) fog, (c) freezing fog, and (d) rain with fog episodes.

turbulence, number of particles, and availability of condensable water-were the main factors influencing the $D_{50}$ position, while different parameters could have played a role at LWCs over $0.1 \mathrm{~g} \mathrm{~m}^{-3}$, in the LWC-independent regime.

Some dependence of the $D_{50}$ on the concentration of accumulation mode particles (considered as all particles larger than $100 \mathrm{~nm}$ in diameter for this analysis) was found during fog and freezing fog episodes (Fig. S9). The smaller $D_{50}$ and thus more effective activation found at low $N_{100}$ concentrations could be the result of a smaller humidity flux to particles, thus allowing higher supersaturation.

The decrease in $D_{50}$, i.e., shift to smaller activated particles can also be seen in the dependence of $D_{50}$ on the LWC in individual clusters (Fig. 11b). There is some variability in the relationship that seems to have been connected to the air mass origin. The $D_{50}$ at low LWC differs from the cluster-higher starting $D_{50}$ values were found during continental clusters (4b, Fig. $11 \mathrm{~b}$ ), and the smallest $D_{50}$ was mostly found during maritime clusters (1b). Similarly, differences were found in the slopes of the decrease and in the homogeneity of the decrease in $D_{50}$, while for continental clusters, the $D_{50}$ decreased by more than $40 \mathrm{~nm}$ per $0.01 \mathrm{~g} \mathrm{~m}^{-3}$ LWC increase, and all $D_{50}$ values were close to the fitted line $\left(R^{2}\right.$ values from 0.63 to 0.84 , Table S4). For maritime cluster $1 \mathrm{~b}$, the slope and $R^{2}$ value were smaller $\left(-20 \mathrm{~nm}\right.$ per $0.01 \mathrm{~g} \mathrm{~m}^{-3}, R^{2}$ value $\left.=0.37\right)$, probably due to lower LWC values recorded during the cluster and partly
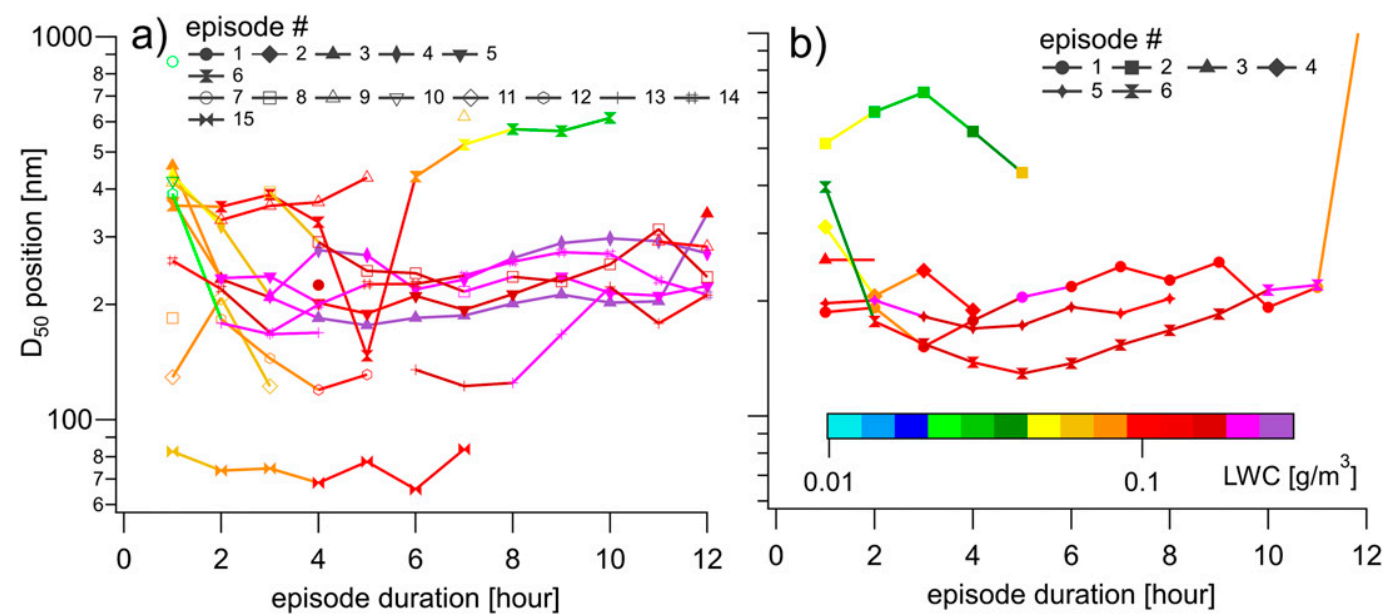

FIG. 10. Time evolution of hourly medians of $D_{50}$ values in the first $12 \mathrm{~h}$ of the episodes of (a) fog and (b) freezing fog that were not preceded by any meteorological phenomena. Different colors represent different LWCs. The lines in the legend denote the measurement campaign in which the episodes were observed. 


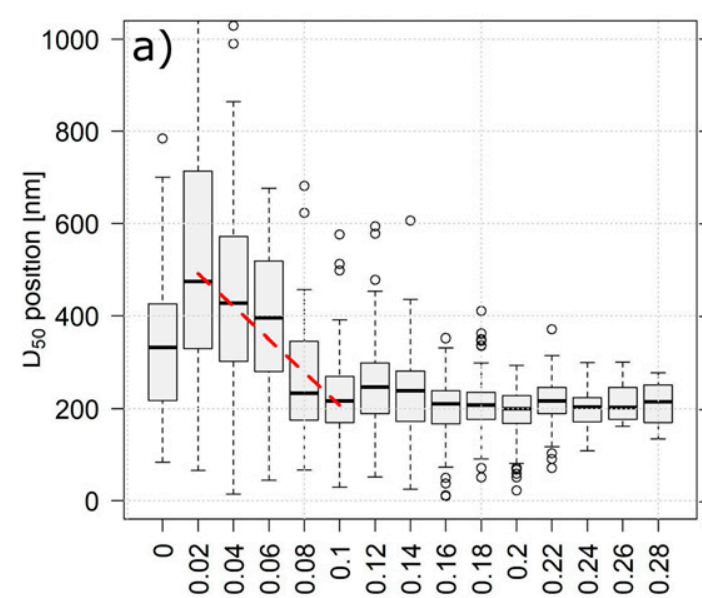

LWC $\left[\mathrm{g} / \mathrm{m}^{3}\right]$

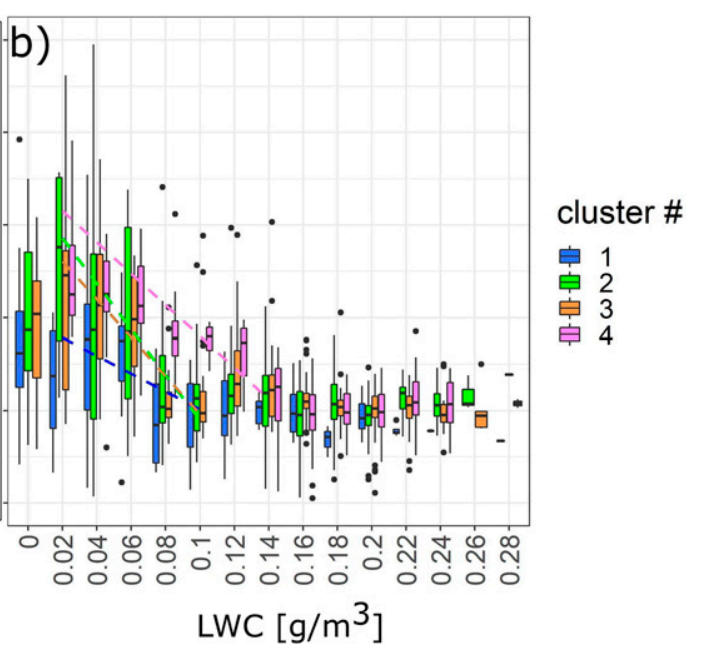

$\operatorname{LWC}\left[\mathrm{g} / \mathrm{m}^{3}\right]$

FIG. 11. Boxplots of the dependence of the $D_{50}$ position during fog/freezing fog/rain on the LWC. The boxplots were calculated from 30 min averages for LWC intervals of $0.02 \mathrm{~g} \mathrm{~m}^{-3}$ for (a) all data and (b) with respect to air mass origin. Lines are linear fits of boxplot medians between 0.02 and $0.10 \mathrm{~g} \mathrm{~m}^{-3}$.

and/or due to different chemical composition of the aerosol in the cluster.

\section{3) $D_{50}$ VS EFFECTIVE RADIUS}

If the effective radius $\left(R_{\text {eff }}\right)$ of the fog droplets was calculated from Eq. (2), the largest radii were found for fog and rain (median $5.2 \mu \mathrm{m}$, Fig. 12), while $R_{\text {eff }}$ during freezing fog was even lower (median $4.5 \mu \mathrm{m}$, the difference was statistically significant). The $R_{\text {eff }}$ was smaller than the results by Henning et al. (2002), who reported an effective radius of approximately $7 \mu \mathrm{m}$. Thus, the effective radius of droplets at Milešovka was approximately $70 \%$ of the $R_{\text {eff }}$ reported at JFJ (Henning et al.
2002) but in accordance with the values from Min et al. (2012), considering the low elevation of the measurements at Milešovka.

The smaller $R_{\text {eff }}$ values were also in correspondence with the lower reported LWC. If Eq. (2) was used for the calculation of the upper boundary of the dependence of $R_{\text {eff }}$ on activated particles with diameters larger than $100 \mathrm{~nm}\left(N_{100}\right)$, LWCs of 0.20 and $0.27 \mathrm{~g} \mathrm{~m}^{-3}$ were found for freezing fog/rain with fog and fog, respectively (Fig. 13). If the same was applied to the NA data, the resulting LWC would be $0.004 \mathrm{~g} \mathrm{~m}^{-3}$.

If $R_{\text {eff }}$ was compared with the air mass origin, the differences were found mainly for cluster $4 \mathrm{~b}$ (Fig. 12b), which was sampled
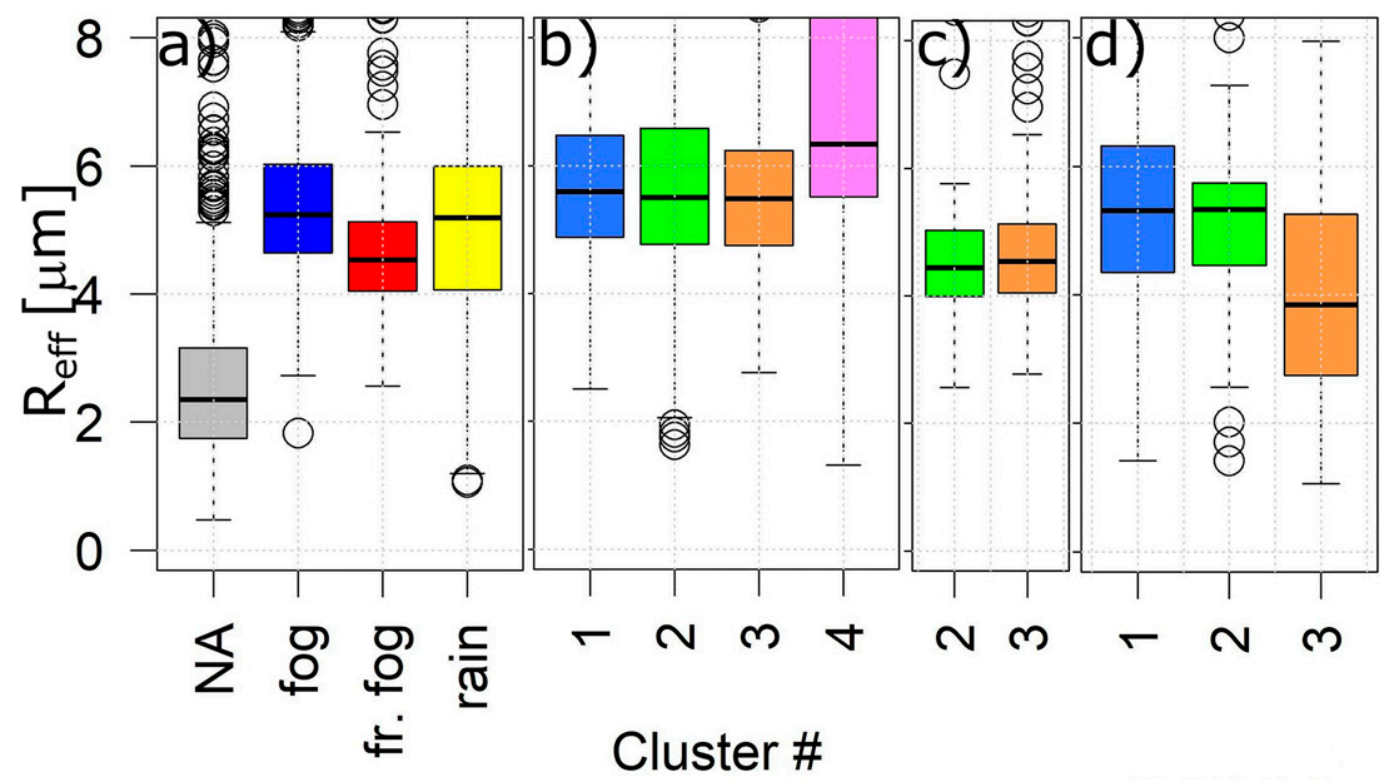

FIG. 12. Boxplots of the effective radius of fog droplets with relation to individual phenomena (a) and clusters with (b) fog, (c) freezing fog, and (d) rain with fog episodes. 


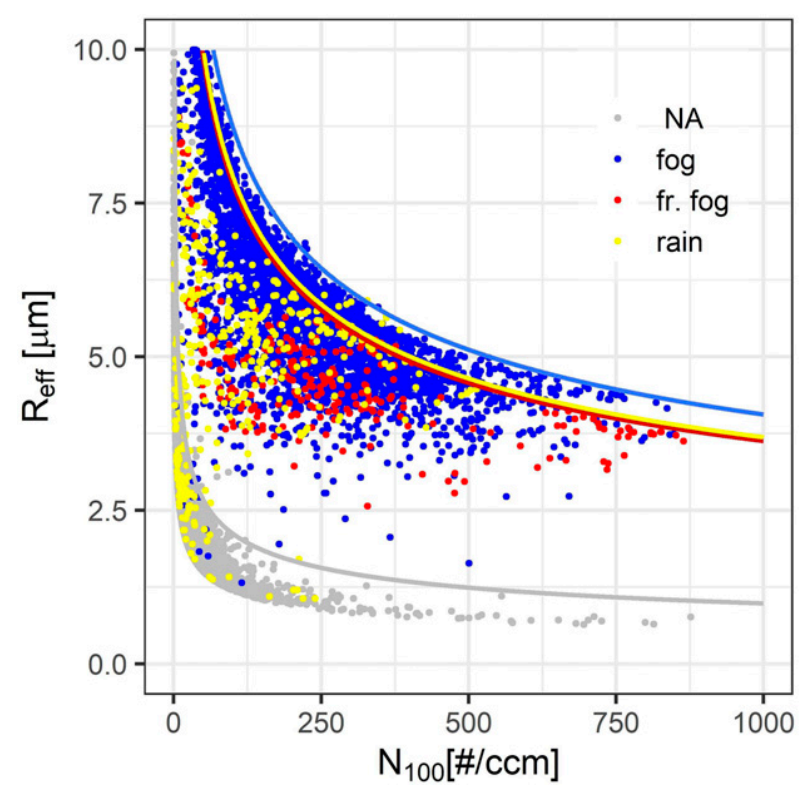

FIG. 13. Dependence of the effective droplet radius on the total number concentration of activated particles with diameters greater than $100 \mathrm{~nm}$ during fog/freezing fog/rain with fog. Lines are calculated from Eq. (2) for LWCs of $0.20 \mathrm{~g} \mathrm{~m}^{-3}$ (red), $0.28 \mathrm{~g} \mathrm{~m}^{-3}$ (blue), $0.21 \mathrm{~g} \mathrm{~m}^{-3}$ (yellow), and $0.004 \mathrm{~g} \mathrm{~m}^{-3}$ (gray).

only during fog episodes. In this cluster, the median $R_{\text {eff }}$ reached $6.3 \mu \mathrm{m}$ and was significantly higher than that in other clusters (which did not show statistically significant differences in $R_{\text {eff }}$ between each other). For freezing fog, the $R_{\text {eff }}(4.5 \mu \mathrm{m})$ was lower than that during fog, independent of the cluster (Fig. 12c). For rain with snow (Fig. 12d), a median $R_{\text {eff }}$ down to $3.8 \mu \mathrm{m}$ in cluster $3 \mathrm{~b}$ was found, which was lower than that during any other phenomenon or cluster due to the low LWC included in Eq. (2). From the upper boundary estimation (Fig. 13), some points in a similar range as freezing fog were also sampled; however, their concentration was smaller. This may have been due to wet scavenging during rain and/or due to the nonsampling of rain drops by the inlets.

\section{Summary and conclusions}

Four intensive in situ campaigns focused on aerosol-cloud interactions were performed in the autumn and spring months from November 2018 to April 2020 at Milešovka Mountain in Czechia to bring more insight into size-dependent aerosol activation and its dependence on its origin for a wide variety of meteorological parameters.

At the observatory, low cloud episodes, coded as fog, freezing fog, or rain with fog, were compared with nonphenomena episodes. Interstitial particle concentrations during these cloud events were found to be lower at all sizes in comparison to episodes without any phenomena observed; wet deposition affected the total PNSD. In the presence of clouds, the mode position of the monomodal PNSD was at larger particles, peaking at 64 and $85 \mathrm{~nm}$ for fog and freezing fog, respectively, compared with $39 \mathrm{~nm}$ during periods without any phenomena observed. Most activated particles were larger than $100 \mathrm{~nm}$, with a mode of the aPNSD over $200 \mathrm{~nm}$. The aPNSD for fog and freezing fog did not differ in shape or concentration. During freezing fog, higher variability in supersaturation or a smaller degree of internal mixing of aerosols were deduced based on the larger $D_{\mathrm{IQR}}$ value in comparison with fog events. Similarly, smaller mean effective radii of cloud droplets were found during freezing fog compared with fog, again suggesting different supersaturation conditions between the two phenomena.

During rain episodes, most results differed from the cloudonly episodes, with the exception of visibility (sometimes exceeding $1000 \mathrm{~m}$ ). A stronger relationship between visibility, effective radius of droplets and air mass origin was observed than for any other phenomenon, probably connected to scavenging of particles-lower concentrations of both interstitial and activated particles were observed. The less effective activation and smaller cloud droplets may have been connected with rainout, which removed part of the water content from the clouds.

The analysis of the relationship between meteorological conditions and activations suggested that the different hydrometeors observed at the observatory were often connected with different air masses with variable conditions. The main difference was found between slow continental air masses and the air mass with a maritime history in the previous three days. For the description of the changes in the activation, no effect of photochemistry was found; in contrast, some dependence on relative humidity, temperature, wind speed, and LWC proved to be useful.

With increasing humidity, smaller particles were found to be able to activate. At $100 \%$ RH, mean-dominated supersaturation was probably observed, with uniform results reported over a wide range of conditions and air mass origins. For lower $\mathrm{RH}$, the importance of supersaturation fluctuations would increase, moving to a fluctuation-influenced regime. In this regime, the mean humidity was not a sufficient variable for a full description of the activation. RH measurements with higher time resolution or supersaturation measurements would be optimal.

The temperature was comparable for fog and rain with fog and of course different during freezing fog. In the dependence of activation on the temperature during fog (and freezing fog as well), the smallest variability in $D_{50}$ (a result of homogeneity in the activation) was found in the temperature interval between $0^{\circ}$ and $+6^{\circ} \mathrm{C}$. For temperatures both lower and higher than between $0^{\circ}$ and $6^{\circ} \mathrm{C}$, the $D_{50}$ position increased, with activated particles larger than $300 \mathrm{~nm}$.

Wind speed did not strongly affect the activation up to velocities of $10 \mathrm{~m} \mathrm{~s}^{-1}$. For wind speeds over $10 \mathrm{~m} \mathrm{~s}^{-1}$, the scatter in the activation increased, probably due to higher turbulence and thus again a fluctuation-influenced regime of activation or due to inversion layer disruption.

The strongest connection was found between activation and LWC; for the LWC below $0.10 \mathrm{~g} \mathrm{~m}^{-3}$, a decrease of $35 \mathrm{~nm}$ in $D_{50}$ (used as a metric for the activation description) was found for every $0.01 \mathrm{~g} \mathrm{~m}^{-3}$ increase in LWC. From $0.10 \mathrm{~g} \mathrm{~m}^{-3} \mathrm{LWC}$ and higher, the $D_{50}$ medians did not vary much and only fluctuated at approximately $200 \mathrm{~nm}$. Thus, for LWCs below $0.1 \mathrm{~g} \mathrm{~m}^{-3}$, in the 
LWC-limited regime, the LWC values and variables effecting the LWC were the main factors influencing the $D_{50}$ position, while different parameters could have played a role at LWCs over $0.1 \mathrm{~g} \mathrm{~m}^{-3}$, in the LWC-independent regime. The smaller activated particles found at low aerosol concentrations could be the result of smaller humidity flux to particles and thus allowing higher supersaturation to be reached.

The next step in describing activation would be an analysis of its connection with the cloud properties; these analyses were not possible in this study due to the missing PVM data, although for the next campaign, these data should be available. Another step forward would be performing chemical analyses of filters collected both in and out of the cloud episodes, and a more detailed measurement of the high-time fluctuations in the humidity field. Such information would allow to estimate the magnitude of the chemical- and meteorology-related changes of activation in individual clusters.

Acknowledgments. This work was supported by the Czech Science Foundation under Grant GJ18-15065Y and by the by the Ministry of Education, Youth and Sports of the Czech Republic, within the project for support of the national research infrastructure ACTRIS-participation of the Czech Republic (ACTRIS-CZ-LM2018122). The authors gratefully acknowledge the NOAA Air Resources Laboratory (ARL) for the provision of the HYSPLIT transport and dispersion model and/or READY website (http://www.ready.noaa.gov) used in this publication. Authors claim no financial conflicts of interests.

Data availability statement. Datasets for this research are available at https://doi.org/10.17632/7zf3r9t53s.1.

\section{REFERENCES}

Abade, G. C., W. W. Grabowski, and H. Pawlowska, 2018: Broadening of cloud droplet spectra through eddy hopping: Turbulent entraining parcel simulations. J. Atmos. Sci., 75, 3365-3379, https://doi.org/10.1175/JAS-D-18-0078.1.

Asmi, E., E. Freney, M. Hervo, D. Picard, C. Rose, A. Colomb, and K. Sellegri, 2012: Aerosol cloud activation in summer and winter at puy-de-Dôme high altitude site in France. Atmos. Chem. Phys., 12, 11 589-11 607, https://doi.org/10.5194/acp-1211589-2012.

Barahona, D., R. E. L. West, P. Stier, S. Romakkaniemi, H. Kokkola, and A. Nenes, 2010: Comprehensively accounting for the effect of giant $\mathrm{CCN}$ in cloud activation parameterizations. Atmos. Chem. Phys., 10, 2467-2473, https:// doi.org/10.5194/acp-10-2467-2010.

Boucher, O., and Coauthors, 2013: Clouds and aerosols. Climate Change 2013: The Physical Science Basis, T. F. Stocker et al., Eds., Cambridge University Press, 571-657.

Ditas, F., R. A. Shaw, H. Siebert, M. Simmel, B. Wehner, and A. Wiedensohler, 2012: Aerosols-cloud microphysicsthermodynamics-turbulence: Evaluating supersaturation in a marine stratocumulus cloud. Atmos. Chem. Phys., 12, 2459-2468, https://doi.org/10.5194/acp-12-2459-2012.

Dusek, U., and Coauthors, 2006: Size matters more than chemistry for cloud-nucleating ability of aerosol particles. Science, 312, 1375-1378, https://doi.org/10.1126/science.1125261.

Fišák, J., D. Rezáčová, and J. Mattanen, 2006: Calculated and measured values of liquid water content in clean and polluted environments. Stud. Geophys. Geod., 50, 121-130, https:// doi.org/10.1007/s11200-006-0006-z.

—_, M. Tesař, and D. Fottová, 2009: Pollutant concentrations in rime and fog water at the Milesovka Observatory. Soil Water Res., 196, 273-285, https://doi.org/10.1007/s11270008-9775-Z.

Gao, Y., M. Zhang, Z. Liu, L. Wang, P. Wang, X. Xia, M. Tao, and L. Zhu, 2015: Modeling the feedback between aerosol and meteorological variables in the atmospheric boundary layer during a severe fog-haze event over the North China Plain. Atmos. Chem. Phys., 15, 4279-4295, https://doi.org/10.5194/acp-15-4279-2015.

Henning, S., E. Weingartner, S. Schmidt, M. Wendisch, H. W. Gäggeler, and U. Baltensperger, 2002: Size-dependent aerosol activation at the high-alpine site Jungfraujoch ( $3580 \mathrm{~m}$ asl). Tellus, 54B, 82-95, https://doi.org/10.1034/j.1600-0889.2002.00299.x.

Hsieh, W. C., A. Nenes, R. C. Flagan, J. H. Seinfeld, G. Buzorius, and H. Jonsson, 2009: Parameterization of cloud droplet size distributions: Comparison with parcel models and observations. J. Geophys. Res. Atmos., 114, D11205, https://doi.org/ 10.1029/2008JD011387.

Jurányi, Z., M. Gysel, E. Weingartner, P. F. Decarlo, L.Kammermann, and U. Baltensperger, 2010: Measured and modelled cloud condensation nuclei number concentration at the high alpine site Jungfraujoch. Atmos. Chem. Phys., 10, 7891-7906, https://doi.org/ 10.5194/acp-10-7891-2010.

Kim, H., and Coauthors, 2019: Chemical processing of watersoluble species and formation of secondary organic aerosol in fogs. Atmos. Environ., 200, 158-166, https://doi.org/10.1016/ j.atmosenv.2018.11.062.

Korolev, A. V., and I. P. Mazin, 2003: Supersaturation of water vapor in clouds. J. Atmos. Sci., 60, 2957-2974, https://doi.org/ 10.1175/1520-0469(2003)060<2957:SOWVIC $>2.0$. CO 2 .

Kushta, J., G. Kallos, M. Astitha, S. Solomos, C. Spyrou, C. Mitsakou, and J. Lelieveld, 2014: Impact of natural aerosols on atmospheric radiation and consequent feedbacks with the meteorological and photochemical state of the atmosphere. J. Geophys. Res. Atmos., 119, 1463-1491, https:// doi.org/10.1002/2013JD020714.

Mandariya, A. K., T. Gupta, and S. N. Tripathi, 2019: Effect of aqueous-phase processing on the formation and evolution of organic aerosol (OA) under different stages of fog life cycles. Atmos. Environ., 206, 60-71, https://doi.org/10.1016/ j.atmosenv.2019.02.047.

Min, Q., and Coauthors, 2012: Comparison of MODIS cloud microphysical properties with in-situ measurements over the southeast Pacific. Atmos. Chem. Phys., 12, 11261-11273, https://doi.org/10.5194/acp-12-11261-2012.

Mircea, M., M. C. Facchini, S. Decesari, S. Fuzzi, and R. J. Charlson, 2002: The influence of the organic aerosol component on CCN supersaturation spectra for different aerosol types. Tellus, 54B, 74-81, https://doi.org/10.3402/tellusb.v54i1.16649.

Motos, G., J. Schmale, J. C. Corbin, R. L. Modini, N. Karlen, M. Bertò, U. Baltensperger, and M. Gysel-Beer, 2019: Cloud droplet activation properties and scavenged fraction of black carbon in liquid-phase clouds at the high-alpine research station Jungfraujoch (3580 m a.s.l.). Atmos. Chem. Phys., 19, 3833-3855, https://doi.org/10.5194/acp-19-3833-2019.

Paramonov, M., and Coauthors, 2015: A synthesis of cloud condensation nuclei counter (CCNC) measurements within the EUCAARI network. Atmos. Chem. Phys., 15, 12 211-12 229, https://doi.org/10.5194/acp-15-12211-2015.

Petters, M. D., and S. M. Kreidenweis, 2007: A single parameter representation of hygroscopic growth and cloud condensation 
nucleus activity. Atmos. Chem. Phys., 7, 1961-1971, https:// doi.org/10.5194/acp-7-1961-2007.

— groscopic growth and cloud condensation nucleus activity Part 2: Including solubility. Atmos. Chem. Phys., 8, 6273-6279, https://doi.org/10.5194/acp-8-6273-2008.

Prabhakaran, P., A. S. M. Shawon, G. Kinney, S. Thomas, W. Cantrell, and R. A. Shaw, 2020: The role of turbulent fluctuations in aerosol activation and cloud formation. Proc. Natl. Acad. Sci. USA, 117, 16 831-16838, https://doi.org/10.1073/pnas.2006426117.

Rangognio, J., P. Tulet, T. Bergot, L. Gomes, O. Thouron, and M. Leriche, 2009: Influence of aerosols on the formation and development of radiation fog. Atmos. Chem. Phys. Discuss., 9, 17 963-18 019, https://doi.org/10.5194/acpd-9-17963-2009.

Reutter, P., and Coauthors, 2009: Aerosol- and updraft-limited regimes of cloud droplet formation: Influence of particle number, size and hygroscopicity on the activation of cloud condensation nuclei (CCN). Atmos. Chem. Phys., 9, 70677080, https://doi.org/10.5194/acp-9-7067-2009.

Rolph, G., A. Stein, and B. Stunder, 2017: Real-time Environmental Applications and Display sYstem: READY. Environ. Modell. Software, 95, 210-228, https://doi.org/10.1016/j.envsoft.2017.06.025.

Rothenberg, D., A. Avramov, and C. Wang, 2018: On the representation of aerosol activation and its influence on model-derived estimates of the aerosol indirect effect. Atmos. Chem. Phys., 18, 7961-7983, https://doi.org/10.5194/acp-18-7961-2018.

Sanchez, K. J., and Coauthors, 2016: Meteorological and aerosol effects on marine cloud microphysical properties. J. Geophys. Res. Atmos., 121, 4142-4161, https://doi.org/10.1002/2015JD024595.

Seinfeld, J. H., and Coauthors, 2016: Improving our fundamental understanding of the role of aerosol-cloud interactions in the climate system. Proc. Natl. Acad. Sci. USA, 113, 5781-5790, https://doi.org/10.1073/pnas.1514043113.

Shawon, A. S. M., P. Prabhakaran, G. Kinney, R. A. Shaw, and W. Cantrell, 2021: Dependence of aerosol-droplet partitioning on turbulence in a laboratory cloud. J. Geophys. Res. Atmos., 126, 1-19, https://doi.org/10.1029/2020JD033799.

Shimadera, H., A. Kondo, A. Kaga, K. L. Shrestha, and Y. Inoue, 2009: Contribution of transboundary air pollution to ionic concentrations in fog in the Kinki Region of Japan. Atmos. Environ., 43, 5894-5907, https://doi.org/10.1016/j.atmosenv.2009.08.022.

Siebert, H., and R. A. Shaw, 2017: Supersaturation fluctuations during the early stage of cumulus formation. J. Atmos. Sci., 74, 975-988, https://doi.org/10.1175/JAS-D-16-0115.1.

Sorooshian, A., and Coauthors, 2019: Aerosol-cloud-meteorology interaction airborne field investigations: Using lessons learned from the U.S. West coast in the design of activate off the U.S. East Coast. Bull. Amer. Meteor. Soc., 100, 1511-1528, https:// doi.org/10.1175/BAMS-D-18-0100.1.

Stein, A. F., R. R. Draxler, G. D. Rolph, B. J. B. Stunder, M. D. Cohen, and F. Ngan, 2015: NOAA's HYSPLIT atmospheric transport and dispersion modeling system. Bull. Amer. Meteor. Soc., 96, 2059-2077, https://doi.org/10.1175/BAMS-D14-00110.1.

Svenningsson, B., and Coauthors, 2006: Hygroscopic growth and critical supersaturations for mixed aerosol particles of inorganic and organic compounds of atmospheric relevance. Atmos. Chem. Phys., 6, 1937-1952, https://doi.org/10.5194/ acp-6-1937-2006.

Tolasz, R., T. Míková, A. Valeriánová, and V. Voženílek, 2007: Atlas podnebí Česka. 1st ed. Český hydrometeorologický ústav, $255 \mathrm{pp}$.

Verheggen, B., and Coauthors, 2007: Aerosol partitioning between the interstitial and the condensed phase in mixed-phase clouds. J. Geophys. Res. Atmos., 112, D23202, https://doi.org/ 10.1029/2007JD008714.

Zhang, Y. W., and Coauthors, 2015: Significant concentration changes of chemical components of PM1 in the Yangtze River Delta area of China and the implications for the formation mechanism of heavy haze-fog pollution. Sci. Total Environ., 538, 7-15, https://doi.org/10.1016/j.scitotenv.2015.06.104.

Zíková, N., and V. Zdimal, 2016: Precipitation scavenging of aerosol particles at a rural site in the Czech Republic. Tellus, 68B, 27343, https://doi.org/10.3402/tellusb.v68.27343.

— _ P. Pokorná, O. Makeš, P. Sedlák, P. Pešice, and V. Ždímal, 2020: Activation of atmospheric aerosols in fog and low clouds. Atmos. Environ., 230, 117490, https://doi.org/10.1016/ j.atmosenv.2020.117490. 